\title{
PRD 1998: TRANSICIÓN INSTITUCIONAL Y RECONVERSIÓN POLÍTICA
}

\section{PRD 1998: INSTITUTIONAL TRANSITION AND CONVERSION POLICY}

\section{AUTOR}

Aléxis Rodríguez Mójica

Facultad de Ciencias Políticas y Sociales. Universidad Autónoma Nacional de México.

alexrodr@hotmail.com

\section{RESUMEN}

Progreso electoral desde 1968 hasta el Referéndum de mayo de 1999. Se nombran acontecimientos como el ocupamiento militar de EEUU, los caminos que toma el PRD en las urnas, el Referéndum de Pérez Balladares y su estancia en el poder, el golpe de estado y la Candidatura unitaria en mayo de 1999

\section{PALABRAS CLAVE}

EEUU - Referéndum - Pérez Balladares - Panamá

\section{ABSTRACT}

Electoral progress from 1968 until May 1999 Referendum. Events are named as the U.S. military occupation, the roads taken by the PRD in the polls, Referendum Balladares and his stay in power, the coup and the bid unit in May 1999.

\section{KEY WORDS}

EEUU - Referendum - Pérez Balladares - Panamá 


\section{ÍNDICE}

\section{Los comienzos del PRD.}

\section{La crisis.}

Las Fuerzas policiales a las cuales el PRD representa llegan al poder el 11 de octubre de 1968, mediante un golpe militar, pero son desplazadas del poder el 20 de diciembre de 1989 a través de la invasión del ejército estadounidense del territorio panameño. Sin embargo, en mayo de 1994, pasados cuatro años, el PRD y sus aliados retornan al poder por la vía electoral: treinta años después de la primera acción, nueve de la segunda, y, cuatro de la tercera, se hace necesario un balance para explicar las formas políticas democrático-liberales que buscan limitar las actuaciones del Estado y sus instituciones a través del cumplimiento de la ley; la representatividad social de los dirigentes políticos; la subordinación de los agentes políticos a los actores sociales, auto-organizados y representables; y la conciencia de la ciudadanía en la cual el derecho constitucional y la Corte Suprema juegan un papel central ${ }^{1}$.

\section{Los comienzos del PRD.}

El modelo democrático liberal se transforma por intermedio de dos rupturas, el golpe de 1968 y la invasión de 1989. Tanto el golpe como la invasión rompen con el orden constitucional y sus formas clásicas de control condicionan de manera solapada la libertad de prensa, de reunión, de asociación y generan un estado de excepción temporal. Porque, por un lado, la acción militar de 1968 cambia el rumbo de los

$1 \quad$ Pérez, Orlando (1998): ¿Democracia o Estabilidad?: La reelección presidencial y sus consecuencias para Panamá en El Canal de Panamá en el siglo XXI. Panamá: S.E., página 312. 
acontecimientos, donde el movimiento popular se perfila como referente inmediato de las transformaciones sociales ${ }^{2}$ y coloca en el escenario a la negociación, como centro del consenso político; por el otro, la invasión retarda una serie de contradicciones, donde el movimiento popular se presenta como interlocutor de demandas sociales distintas y coloca a la confrontación política como única vía para enfrentar la ocupación de país.

Pero, ni el Golpe, ni la invasión rompen las relaciones subyacentes en la economía: continúan las operaciones de los negocios de la oligarquía y los sectores de la burguesía industrial y comercial; la inversión y la extensión en la aprobación de la tierra, también por la Oligarquía y la burguesía agraria; y la asociación del capital comercial y financiero nacional con el capital financiero transnacional. Ambas intervenciones militares, una interna y otra externa, facilitan eso sí, la renovación en su forma, pero no en su contenido, del sistema de dominación panameño, compuesto por estructuras de poder familiar, modos decimonónicos de ejercicio del poder; y formas de mediación constitucional y de representatividad delegativopartidaria.

Con la invasión, la situación neocolonial se rompe y el modelo de control, intervención y mediación planteado por los militares interlocutores de los Estados Unidos en el país e iniciado en 1950 y consolidado en 1968, termina abruptamente. Se retorna, entonces, a la situación colonial que cristaliza en 1925; en la cual, los Estados Unidos intervienen de manera directa y media de manera indirecta en cuestiones domésticas y electorales entre las fracciones de la Oligarquía (Oligarquía comercial y casateniente -y- las fracciones de la Oligarquía terrateniente) y la burguesía ascendente; y entre la Oligarquía y la Burguesía ascendente, y, el movimiento popular, tal como se registra el 5 de diciembre de 1990.

$2 \quad$ El Golpe rompe con el acumulado organizativo e histórico del movimiento popular, que aún resulta difícil de remontar. Este hecho muestra, en la práctica la efectividad del golpe de Estado y su propuesta organizativa, el PRD. 
Posteriormente, surgen otras mediaciones institucionales que en su conjunto asumen las funciones ejecutadas, en su momento, por el aparato militar y los EEUU. Tal es el caso de la Comisión de Justicia y Paz, que intenta mediar entre las fuerzas políticas en conflicto a través del compromiso Ético Electoral de Santa María La Antigua; el Defensor del Pueblo, que busca mediar entre el Gobierno y el pueblo; y, los Encuentros de Bambito y Encuentros Panamá 2000 realizados en Coronado e impulsados por Naciones Unidas, cuyo propósito es concertar posiciones entre los sectores que conforman la sociedad ${ }^{3}$. Con ello las formas de mediación y los mecanismos de control se hacen cada vez más complejos y poco a poco reemplazan las formas históricas de representación y mediación conocidas impuestas 0 establecidas antes, durante y después de 1968.

En 1994 el PRD retorna al poder por la vía electoral. Cuatro años antes, en 1989, era desplazado del poder mediante la invasión del Ejército de los Estados Unidos al territorio panameño. Sin embargo, la victoria electoral del PRD es la expresión de una experiencia truncada, pero intentada desde los sectores populares a través de la coordinadora de Organizaciones Populares en 1987; el comité Pro-Rescate de la Soberanía en 1990; la Jornada Nacionalista y Democrática en 1991 (pero creada en 1988); y, la coordinadora por el Derecho a la Vida en 1992. Entre 1987 y 1994 no fue posible crear una plataforma política, ni electoral con capacidad de trabajo e inserción en sectores sociales concretos, ni en espacios geográficos determinados. Aunque si fue posible, en la práctica, y mediante la presión organizada, colapsar la aplicación del Plan de Modernización de la Economía desde 1984 hasta 1995.

El retorno del PRD al poder tiene diversos referentes. Sin embargo, es el retorno de sus cuadros intermedios a diversos espacios organizativos lo que sostiene la

\footnotetext{
3 La relación mediaciones institucionales y modelo democrático liberal las sintetiza Leis, Raúl, (1998): Concertaciones y Gobernabilidad Democrática: límites y posibilidades para la Democracia panameña en el Canal de Panamá en el siglo XXI. Panamá: S.E., Página, 323.
} 
dinámica de ese colectivo político y hace posible la consigna electoral de "El pueblo al poder". Pero, en la recaptura del Estado por el PRD, la figura de Pérez Balladares, se convierte en pieza central del proyecto de reformas de la economía y del Estado. Pérez Balladares ${ }^{4}$ logra aglutinar en torno a su candidatura, primero, y en su gobierno, después, sectores diversos porque cuenta con vínculos económicos en la exportación cafetalera, vínculos con las familias Vallarino, Pretelt y González Revilla, y comprobada experiencia en la gestión económica y política del Estado.

Ese consenso que se gesta en torno a la figura de Pérez Balladares se amplía durante su gestión gubernamental (1994-1998) y al mismo tiempo facilita que el proyecto de reelección sea un hecho. Pero a lo largo de su gestión, ese consenso se amplía y le propone de optar por la reelección presidencial directa a través de cambios constitucionales y mediante la convocatoria a referéndum. Según Pérez Balladares, esa aventura es posible porque las encuestas lo permiten: su persona en tanto figura política cuenta con un estable $60 \%$ de aprobación y su esposa Dora Boyd de Pérez Balladares, con un $90 \%$ de aprobación en las encuestas realizadas a lo largo de su gestión presidencial $\left.\right|^{5}$.

El 30 de agosto de 1998, nueve meses antes de las elecciones generales de 1999 se

\footnotetext{
4 Pérez Balladares, entre 1971 y 1975 trabaja en el City Bank-Panamá como Gerente de Crédito y Planificación de Crédito Corporativo para Panamá y Centroamérica. También fue miembro de la Comisión de Legislación de 1975 a 1976; Ministro de Hacienda y Tesoro entre 1978 y 1981; Ministro de Planificación y Política Económica de 1981 a 1982, cuando impulsa el primer programa de Ajuste Estructural (PAE) que inicia su aplicación en 1983. Además dirige la campaña política de la Candidatura de Carlos Duque, en 1989; y es electo sucesivamente Secretario General del PRD y Presidente de la República, por la Alianza Pueblo Unido, para el período 1994-1999. Estas tareas realizadas tanto para el capital nacional como para el capital transnacional son las que sostienen el consenso en torno a la figura de Pérez Balladares, como gestor de un proceso de cambios y seguro interlocutor de sectores y grupos económicos.

5 Moreno, Javier (1998). Ernesto Pérez Balladares, Presidente de Panamá: "La relación con EEUU ha sido traumática este siglo". Madrid, El País, Miércoles, 21 de octubre, no 901
} 
establece como fecha para realizar el referéndum ${ }^{6}$ para la reelección directa de Pérez Balladares. Ese proyecto de reelección inaugura un escenario donde las instituciones del liberalismo ístmico -entre ellas, el clientelismo, el capitalismo del juega vivo- ya no ocupan un lugar privilegiado en la consolidación de los procesos políticos y económicos. El referéndum muestra, en su conjunto, la crisis generalizada de las formas de gestión política practicadas por el PRD, sean las mismas históricas (el caudillismo-populista, como mediación desde arriba) o políticas (implantación de la pequeña burguesía y las capas medias en el Estado, como mediación desde en medio. Esta última, entre otras situaciones, es la que explica el apoyo crítico al reformismo burgués, primero, en los años 70 y pequeño burgués después de la década del 70 , por diferentes segmentos de los sectores intelectuales y organizados en el movimiento popular.

El referéndum como propuesta política, es el canal escogido por la dirección del PRD para superar su crisis interna de dirección y colocarse en posibilidad de aumentar su capacidad de gestión política. Con ello el PRD deja atrás las políticas sociales como estrategia de contención política y abandona su programa histórico de redistribución de la renta, soberanía nacional y ampliación del mercado interno. Esta ruptura del PRD no tiene referentes concretos en Congresos, ni en reuniones ampliadas para debatir la estrategia a seguir ante los cambios en el mundo. Esa convocatoria evidencia una crisis interna en el PRD, y representa en la práctica una reducción de la clientela política; una disminución del margen de maniobra del gobierno; un distanciamiento entre la base política, el partido de masas y la dirección política. Este problema partidario, en conjunto con la movilización generalizada de la oposición y la

Con anterioridad se realizan consultar populares el 23 de octubre de 1977 para ratificar los Tratados del Canal; en la misma participa el 97,3\% de la población electoral, es decir, 766.232 personas. Cinco años después, el 24 de abril de 1983, se convoca otra consulta popular para modificar la constitución de 1972 y garantizar la transición democrática iniciada en 1978; participa de la misma el $66,8 \%$ de la población electoral que representan unas 556.969 personas. Nueve años más tarde, el 15 de noviembre de 1992, se convoca una consulta popular para eliminar constitucionalmente, el Ejército; en dicha convocatoria participa el $40,1 \%$ de la población electoral, unas 559.651 personas. 
unidad en la práctica de los sectores populares incide y provoca el eventual NO a la reelección presidencial directa de Pérez Balladares.

El resultado del referéndum permite lecturas políticas de todo tipo. A lo largo del debate post-referéndum se muestran sólo aquellas que son representativas de opciones políticas concretas, en muchos casos institucionales. Pero, entre ellas está ausente un balance desde la administración Pérez Balladares. Este hecho resulta una contradicción para sus bases sociales, porque "se supone que los partidos políticos son instituciones democráticas e interés público"7. Por su parte Pérez Balladares reduce el problema de la derrota a la relación reelección y dictadura civil8 ${ }^{8}$.

El proyecto de reelección es rechazado en una proporción de 2 a 1 por la población electoral que acude a las urnas. En esta experiencia participa el $66 \%$ de la población electoral o sea 1.106 .752 personas. La reelección es apoyada por el 34\% de los votantes, es decir 379.671 personas. Es decir, la intención de votos para con el bloque conformado por el PRD, como partido homogénico, aumenta en 24.445 personas con relación a 1994, donde obtiene el apoyo de 355.307 personas y con ello alcanza la Administración del Estado. Lo que supone una alta participación de los miembros de dicho colectivo que según el Tribunal Electoral, cuenta, en ese momento, con 383.000 agiliados $9^{9}$.

No obstante, el referéndum es el tercer ejercicio donde se coloca a prueba su capacidad de convocatoria del PRD. Dicho ejercicio permite observar que el PRD se mantiene entre el 27\% de UNADE en 1984, pasando por el 19\% de COLINA en 1989 -a falta de mesas por contar- y el $33 \%$ de preferencia electoral alcanzado por la

\footnotetext{
7 Guerra, Ramiro, 1998). “El discurso en la política”, EPASA, El Panamá América, Opinión, martes 29 de septiembre.

$8 \quad$ Moreno, Javier, 1998. Ernesto Pérez Balladares, Presidente de Panamá: "La relación con EEUU ha sido traumática este siglo". Madrid, El País, miércoles 21 de octubre, № 901

9 El Siglo Digital. 1998. Panamá, Lunes 26 de octubre
} 
Alianza Pueblo Unido en 1994. El incremento gradual del porcentaje de preferencia electoral tiene, entre otras, su explicación en la incorporación plena del Partido Laborista (PALA), el Partido Republicano (PR), el Partido Panameñista Revolucionario (PPR), el Partido del Pueblo (PP) y el Partido Revolucionario de los Trabajadores (PRT) a la estructura organizativa del PRD. Anteriormente se habían incorporado al PRD el Frente Amplio Popular (FRAMPO) y el Partido Democrático de los Trabajadores (PDT).

El consenso histórico del conjunto de esas fuerzas representa un margen estable del $30 \%$ de preferencia electoral: esto significa que la base social del PRD es estable, $y$, en especial, que sus planteamientos, una evolución del liberalismo radical cuentan con apoyo y presencia nacional; al mismo tiempo sugiere, que los Partidos Solidaridad ${ }^{10}$ y Cambio Democrático ${ }^{11}$ no representan en realidad un amplio caudal de votos, ni tienen una base social importante, aun cuando sí representan un aporte monetario significativo.

Porque sobre todo, los partidos Solidaridad y Cambio Democrático, tienen entre su base social a los miembros renegados y descontentos, en momentos coyunturales,

El Partido Solidaridad representa los intereses del Grupo que posee el control sobre las empresas Cervecería Nacional, Banco del Istmo, Construcciones Nacionales, Banco Sur, Metalforma, Cervecería Chiricana, entre otras. Estos grupos económicos fueron unidos a las elecciones generales de 1994 y levantaron una candidatura presidencial propia. Una vez Pérez Balladares es declarado Presidente de la República por el Tribunal Electoral, estos sectores económicos negocian con el PRD y permiten el control de la Asamblea Legislativa, un espacio estratégico y necesario para la aprobación de distintas leyes y proyectos que componen el Programa de Modernización Económica. Luego del referéndum y por la carencia de arraigo en sectores sociales concretos, se replantean su participación en una alianza donde el PRD sea el partido hegemónico. Aún así, esa alianza encabezada por el PRD, es la que para ellos representa las mejores opciones y espacios de actuación. La candidatura de Alberto Vallarino, les proporciona a ese mismo grupo, un conjunto de garantías en la continuidad del proyecto encabezado por Pérez Balladares, ahora bajo la perspectiva socialcristiana. El proyecto de Nicolás Ardito Barletta y Ernesto Pérez Balladares, parece encontrar en Alberto Vallarino, el continuador más preclaro de la economía social de mercado, es decir, de las contrareformas económicas propuestas desde 1983

11 Económicamente, el Partido Cambio Democrático lo sostiene el Grupo Martinelli integrado de manera relevante por las empresas Super 99, importadora Ricamar, Molino del Norte, S.A. 
con la política de gestión del Estado, en este caso del PRD. Algo similar se registra con la aparición de los partidos Unión Democrática Independiente (UDI), Partido Panameñista Doctrinario (PPD), Movimiento de Renovación Nacional (MORENA), entre otros, en el período de 1992-1993. Y la reorganización del Partido Liberal Nacional de Raúl Arango, durante la administración de Pérez Balladares. No obstante, lo interesante del ejercicio de 1998, según Marco A. Gandásegui, h., es que siendo rechazado por la población, el programa de la administración Pérez Balladares, su aplicación no se detiene, continúa ${ }^{12}$.Esto confirma, contrario a lo expuesto desde el PRD, que el referéndum tenía un sólo eje, la continuidad de Pérez Balladares en la dirección del Estado. Tal como se señaló desde distintos espacios políticos y como lo muestran, también, las tres candidaturas emergentes (asociadas al proyecto de Pérez Balladares) de Tomás Gabriel Altamirano Duque, Francisco Sánchez Cárdenas y Martín Torrijos, una vez es derrotado el proyecto para la reelección directa. Esas candidaturas se encuentran vinculadas de manera directa al proyecto de reelección directa y hacen parte de la gestión gubernamental de Pérez Balladares con la cual tienen muchas afinidades demostradas en la práctica.

Es por ello que el margen de votos a favor del SI, representan tanto la aprobación de la gestión económica como del proyecto impulsado por la Administración Pérez Balladares. El voto a favor de la reelección es el margen de maniobra real que posee el continuismo burocrático, y, al mismo tiempo, la ratificación de un proyecto económico y político de contra-reformas más radicales que los ajustes estructurales de la década de los ochenta.

Pero, ¿qué hubiese sucedido si la política económica de Pérez Balladares se aplica por consenso y compensa a los sectores económicos y sociales sensitivos? Acaso,

12 Gandásegui, Marco A., (1998). La reelección presidencial en Panamá. Pueblo Panameño rechaza política Neoliberal de Pérez Balladares. Panamá. Cela, 13 pág. 
entonces, ¿Pérez Balladares no sería un candidato presidencial con posibilidades electorales reales? La respuesta queda pendiente. Pero, sin duda, la política de paz social mediante la asistencia preventiva ya mostró su efectividad con el régimen de Torrijos y puede convertirse en el eje de las convocatorias legislativas de diversos candidatos del PRD y la Democracia Cristiana.

La otra dinámica que deja en evidencia el Referéndum, es la desconexión entre la dirección del PRD y su base social. Esta situación se hace evidente cuando la gestión del PRD, encabezada por Pérez Balladares ataca, disminuye y liquida el espacio de maniobra de su propia base social a través de dos situaciones, la primera, cuando se flexibiliza y reforma el Código Laboral; la segunda, cuando se privatizan las empresas públicas. La reducción del aparato del Estado significa para las bases del PRD y para su clientela política, cambios radicales en la relación Partido-Estado. Para el conjunto de la población empobrecida por la política económica significa el incremento del costo de la vida. Pero la relación entre rechazo, movilización y protesta contra el programa económico no aflora todavía de manera muy clara.

\section{La crisis.}

En eso consiste la "evidente" crisis en el pacto histórico de dominación sobre el cual descansa el PRD, un partido de corte burgués por el carácter de sus reivindicaciones, que coloca al Estado como escenario privilegiado de la lucha de clases; la correlación de fuerzas se formaliza a partir del número de instituciones que están bajo uno y otro control, siendo entonces las huelgas un medio para el ajuste y la modernización de las políticas del Estado. Ese es el sustrato de las históricas jornadas de Lucha de 
FENASEP ${ }^{13}$.

La crisis de las formas de relación política construidas desde 1972 tiene, sin embargo, múltiples referentes. Porque si la base social del PRD se conforma a partir de la relación clientela-gestión del Estado, entonces la apropiación del Estado juega un papel importante en la política partidaria. Con el adelgazamiento del Estado lo que se reduce es la capacidad de maniobra de la dirección política de ese colectivo. También se restringen las posibilidades de ampliar la base social del PRD; porque la base social no puede ampliarse por intermedio de la Carrera Administrativa, una vez el PRD es desplazado del Estado.

La Carrera Administrativa le permite a todo ciudadano optar por un cargo en el Estado y convertirse en parte del mismo y no de aparato militante del PRD, en su gestión de gobierno. La Carrera Administrativa resulta de esa forma, insuficiente para solventar las necesidades del PRD. Como Partido, el PRD solo conoce, como experiencia relevante, la gestión del Estado. El ejercicio del poder y la administración del Estado es el espacio cuasi natural del PRD. Una derrota electoral significa, entonces, el colapso de la vida partidaria y su traspaso a las organizaciones gremiales que dicho colectivo controla o donde tiene incidencia.

Porque la membresía que sostiene políticamente la estructura del PRD no tiene el control de empresas donde colocar al resto de sus cuadros; tampoco tiene grandes extensiones de tierra que ceder para que sus cuadros puedan resolver sus necesidades básicas. Pero, cabe preguntarse ¿cómo un sector con esas características y que económicamente no es relevante (la pequeña burguesía: pequeña propiedad y pequeña producción con vínculos directos con el tránsito) aparece en lo político como el sustituto -en ascenso- de la burguesía industrial,

13 Turner, Jorge: La Nueva Etapa Sindical en Panamá (1984-1988) en Sindicatos, Nuevos Movimientos Sociales y Democracia. México: Universidad Obrera, páginas 113-118. 
aliado histórico en los proyectos de paz social y consenso ideológico retomadas por el PRD?

El resultado del referéndum representa eso sí, un colapso en frío de las opciones políticas del PRD pero todavía no, su derrota electoral; como supone la oposición y en especial el triunfalismo Arnulfista encabezado por Mireya Moscoso, gerente y propietaria de ARKAPAL, URBANA, DONAGA, empresas vinculadas con la construcción, la ganadería y los cafetales. No obstante, el temprano triunfalismo arnulfista se desdibuja en la medida que la candidatura de Alberto Vallarino es apoyada por la Democracia Cristiana y se amplían las posibilidades de una postulación presidencial de Mayín Correa. Con la fusión de intereses políticos entre el grupo que representa Alberto Vallarino y la DC el espacio de representación de sectores periféricos vinculados a PROQUIMSA, Metalquímica, S. A., Productos Químicos, S.A., Sulfatos del Perú, S.A., entre otros, se extiende y constituye un frente homogéneo.

Esto último sugiere que esos sectores de la burguesía y la pequeña burguesía cuentan con una estrategia definida sobre el problema del poder y por eso se plantean su captura al margen de las concesiones populistas del Arnulfismo. También representa el avance conservador e ideológico de un sector social relegado durante años a un segundo plano, en las candidaturas presidenciales.

Esa distribución requiere de un análisis con detenimiento, por las implicaciones de su discurso unitario-conservador. Pero, quizás y sólo quizás, lo que emerge después del referéndum en forma de separación entre las bases del PRD, su dirección política y Ernesto Pérez Balladares sea también parte de una estrategia -no explícita- para acercar a quienes intentan reeditar la antigua alianza del 70, hoy sin capacidad objetiva y sustrato económico donde asentarse. 
El discurso populista y regulacionista, por el contrario, puede encontrar amplios espacios de realización porque, acaso no ha sido esa la estrategia a lo largo de los primeros 20 años del proceso reformista; acaso la decantación de sus figuras intermedias y su participación en asociaciones gremiales no es la forma de consenso ampliado dentro del PRD. Esto no significa, en ningún sentido, la incapacidad, ni la imposibilidad de distintos sectores al interior del PRD de gestar un giro hacia un gobierno consenso para enfrentar las elecciones de 1999; en especial y, porque la composición social del PRD permite reiteradas composiciones: el problema parece ser el rejuego interno en el PRD y su unidad ante la ausencia de la institución militar encargada de homogeneizar las posiciones políticas y encontrar un consenso interno.

En tanto el PRD es, por su contenido, un partido de corte burgués, por su forma de conducción pequeño burgués. Esto se muestra de manera abierta en las candidaturas más relevantes a la Presidencia de la República al interior del PRD donde se disputan por abajo, la pequeña burguesía y las capas medias la interlocución del proyecto propuesto por la oligarquía, la burguesía comercial y, por arriba, los sectores económicos buscan un nuevo interlocutor.

Ese escenario de tensiones entre fuerzas sociales no presagian el resquebrajamiento y ni la ruptura del PRD porque los sectores sociales expresados en las Candidaturas de Gustavo García Paredes y Pablo Arosemena, se incorporan en este década al PRD con la idea de reorganizar su dirección y sostener contradicción sobre la cual descansa ese partido; donde existe una disputa desde su fundación.

Esa contradicción configura su ambigüedad como opción política. Ambas candidaturas, representan eso sí, la incorporación de sectores democráticos, independientes y periféricos a las concepciones de reformas progresivas planteadas desde el PRD. En descubrir el entramado que hace posible esa compleja vida 
partidaria consiste el debate de fondo después del referéndum: en conocer ¿cuál es el fundamento de la contradicción constitutiva de ese colectivo político? y, ¿cómo alcanza a incorporar a diversos sectores sociales sin mayores complicaciones internas?

\section{Conclusión.}

El resultado del referéndum no coloca en opción delegativa a la oposición, se la misma encabezada por Mireya Moscoso (PA), Alberto Vallarino (PDC), Mayín Correa (MCN). Esa carencia de representatividad significa una ausencia de conducción y también de dirección. El NO a la reelección directa permite observar, una vez más, el desmedido apetito de poder y en medio de ello las deficiencias del liderazgo y la ineficiente conducción partidaria-opositora. Quedan al descubierto las carencias, dificultades y pugnas entre las facciones burguesas que conforman la oposición y los reductos reales de la oligarquía.

Nuevamente, se reproduce al interior de esos sectores los mismos síntomas que desataron la crisis de 1968 cuyo desenlace termina con el golpe de Estado y la emergencia de un tipo distinto de pacto de dominación encabezado por los militares. Esta misma disputa es la que impide a los sectores de la derecha criolla marchar unidos en las elecciones de 1994; y es también lo que estructura las contradicciones para una Candidatura unitaria, impulsada por esos sectores, en mayo de 1999.

Existe consenso en el proyecto de tránsito, pero no la homogeneidad necesaria para la reagrupación de las fracciones opositoras que tienen diferencias de fondo y de forma para configurar un proyecto unitario, estratégico en sus aspiraciones de aprovechar en distintas formas la venta de las áreas periféricas al Canal, a su favor. 